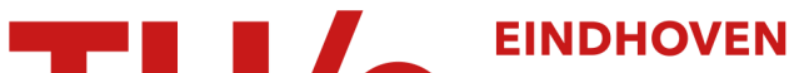 UNIVERSITY OF TECHNOLOGY
}

\section{Grass field detection for TV picture quality enhancement}

Citation for published version (APA):

Zafarifar, B., \& With, de, P. H. N. (2008). Grass field detection for TV picture quality enhancement. In International Conference on Consumer Electronics, 2008. ICCE 2008. Digest of Technical Papers, 9-13 January 2008, Las Vegas, Nevada (pp. 1-2). Institute of Electrical and Electronics Engineers.

https://doi.org/10.1109/ICCE.2008.4587982

DOI:

10.1109/ICCE.2008.4587982

Document status and date:

Published: 01/01/2008

\section{Document Version:}

Publisher's PDF, also known as Version of Record (includes final page, issue and volume numbers)

\section{Please check the document version of this publication:}

- A submitted manuscript is the version of the article upon submission and before peer-review. There can be important differences between the submitted version and the official published version of record. People interested in the research are advised to contact the author for the final version of the publication, or visit the $\mathrm{DOI}$ to the publisher's website.

- The final author version and the galley proof are versions of the publication after peer review.

- The final published version features the final layout of the paper including the volume, issue and page numbers.

Link to publication

\section{General rights}

Copyright and moral rights for the publications made accessible in the public portal are retained by the authors and/or other copyright owners and it is a condition of accessing publications that users recognise and abide by the legal requirements associated with these rights.

- Users may download and print one copy of any publication from the public portal for the purpose of private study or research.

- You may not further distribute the material or use it for any profit-making activity or commercial gain

- You may freely distribute the URL identifying the publication in the public portal.

If the publication is distributed under the terms of Article $25 \mathrm{fa}$ of the Dutch Copyright Act, indicated by the "Taverne" license above, please follow below link for the End User Agreement:

www.tue.nl/taverne

Take down policy

If you believe that this document breaches copyright please contact us at:

openaccess@tue.nl

providing details and we will investigate your claim. 


\title{
Grass Field Detection for TV Picture Quality Enhancement
}

\author{
Bahman Zafarifar ${ }^{1}$ and Peter H. N. de With ${ }^{2}$, IEEE Fellow \\ ${ }^{1}$ NXP Semiconductors, ${ }^{2}$ Eindhoven University of Technology, ${ }^{3}$ Philips Consumer Electronics
}

\begin{abstract}
Current TV image enhancement can be improved if the image is analyzed, objects of interest are segmented, and each segment is processed with content-specific enhancement algorithms. In this paper we present an algorithm for segmenting grass areas in video sequences. The system employs multi-scale texture analysis and adaptive color and position models for computing a pixe-based soft segmentation map. Compared to previously reported algorithms, our system shows a clear improvement in the detection result: at $10 \%$ false positive rate, the true positive rate of our algorithm yields $91 \%$, vs. $66 \%$ and $58 \%$ of two existing methods.
\end{abstract}

\section{INTRODUCTION}

Image enhancement in current TVs is performed globally, e.g. contrast and brightness, or it is adapted to the local properties of a small pixel neighborhood, e.g. selecting only pixels that are likely to be part of a single object [1]. The latter locally-adaptive method can be improved if the adaptation is extended towards a more elaborate analysis of the image, in order to consider the true nature of the video content. Such content-based adaptation can be realized by analysis and segmentation of objects of interest using a number of detectors, followed by optimized processing of each segmented area. Based on this concept, we previously developed an algorithm for detecting sky areas in TV images [2]. In this paper we extend this concept with another object detector, which reuses the developed techniques, in order to come to a more universal solution.

Grass fields are frequently seen in sports programs and outdoor scenes. This motivates the subjective importance of image enhancements in grass areas. Previously reported work on grass detection for real-time video includes a method based on pixel-level color and texture features [3]. To reduce the variations in the detection result of this pixel-based approach, [4] proposes $8 \times 8$ block averaging of a color-only grass detector and a binary classification to grass/no-grass classes. We developed a method that extends these algorithms with better color and texture features, multi-scale image analysis, and modeling of grass areas prior to a pixel-accurate soft segmentation.

\section{ALGORITHM DESCRIPTION}

We propose a detection system (Fig. 1) that is based on 1) analyzing the image using color and texture features, 2) modeling the object (grass areas) by color and position models, and 3) computing a pixel-accurate soft segmentationmap by using the input image and the mentioned models.

This work was funded by Philips Consumer Electronics, Belgium. The publication is sponsored by NXP Research, The Netherlands. We also acknowledge Dr. Erwin Bellers for his input on the existing algorithms.

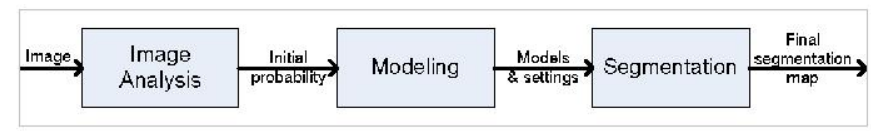

Fig. 1. System overview.

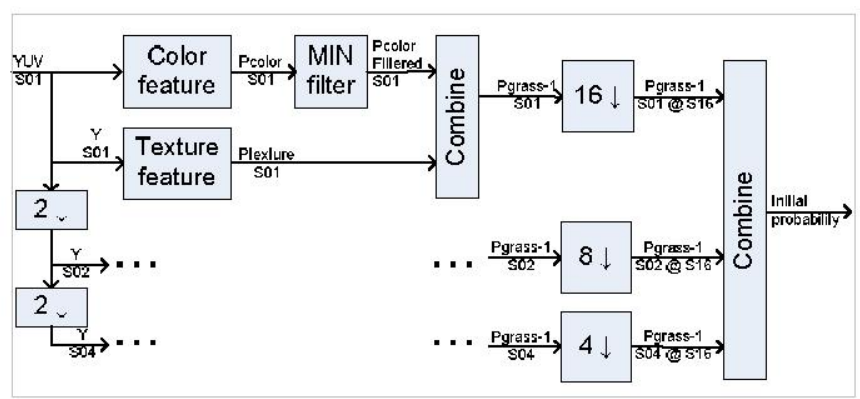

Fig. 2. Block diagram of the Image Analysis stage.

\section{A. Image Analysis}

Fig. 2 depicts the image analysis stage. The texture feature,

$P_{\text {texture }}(i, j)=a b s\left(Y\left(i_{i j}\right)-\frac{Y\left(i_{j},-1\right)+Y\left(i_{j}, 1\right)}{2}\right)+a b s\left(Y\left(i_{i, j}\right)-\frac{Y(i-1, j)+Y(i+1, j)}{2}\right)-t_{0}$,

uses the absolute difference between the current pixel and the average of two neighboring pixels in the vertical and horizontal directions ( $t_{0}$ is a noise-dependent threshold). This feature performs better in rejecting spatial gradients than the root-mean-squared pixel differences used in [3].

The color feature (Fig.2) uses a 3D Gaussian function in the YUV color space, centered at the spatially constant average grass color. To ensure a compact representation, the parameters of the 3D Gaussian (prescribing the center, orientation and variance) are determined by Principal Component Analysis (PCA) of the color of the grass areas of a manually annotated training set. The proposed feature performs better than the color feature of the existing algorithms, by exploiting the correlation between the grass color components. The color feature is further filtered using a minimum filter (MIN in Fig.2), to prevent edges of non-grass green objects from being wrongly detected as grass.

Fig. 2 shows that the image-analysis stage implements a multi-scale approach, in which the result of the analysis on different image scales are down-scaled and combined together, producing the initial probability of grass. With this approach, a wide range of grass texture can be detected, for example grass fields of both far-away and close-up scenes.

The initial probability contains spatial variations within grass fields, caused by non-uniform texture distribution and lower resolutions of the multi-scale analysis, and may therefore not satisfy the requirements of some post-processing 
applications. To address this problem, we propose using this initial grass probability to model the grass areas by color and position models (Fig. 4-b and c), and then to employ the models in re-computing a pixel-accurate final grass segmentation map, using the input image at full resolution. This is described in the following two sections.

\section{B. Modeling}

The color model is a spatially varying value, representing the estimated grass color at each image position (Fig. 4-b). The color model is implemented using three small $(h \times w)$ matrices, $M_{Y}, M_{U}$ and $M_{V}$, one for each color component. As an example, the luminance color model $M_{Y}$ is defined as

$$
M_{Y}(r, c)=\frac{\sum_{i=-h}^{h} \sum_{j=-w}^{w}\left(Y(r+i, c+j) \times P_{\text {initial }}(r+i, c+j) \times W(i, j)\right)}{\sum_{i=-h}^{h} \sum_{j=-w}^{w}\left(P_{\text {initial }}(r+i, c+j) \times W(i, j)\right)},
$$

which fits $M_{Y}$ to the values of the corresponding color component $Y$ of the input image, using a Gaussian kernel $W$, weighted by the initial grass probability $P_{\text {intial. }}$. This ensures that the color model is not influenced by parts of the image that are initially not considered as grass.

The position model $P_{\text {position }}$ is a smooth version of the initial grass probability, obtained by filtering with a Gaussian kernel. This model is implemented as a small $(h \times w)$ matrix of values.

The above model-creation procedure is computationally expensive, but the small resolution of the models $(h \times w$ is 16 times smaller than the input image) reduces the amount of computations. The models are up-scaled to the input image resolution in the computation of the final segmentation.

\section{Segmentation}

A pixel-accurate soft segmentation-map,

$$
P_{\text {final }}=P_{\text {colorFinal }} \times P_{\text {position }} \text {, }
$$

is computed in the segmentation stage, using the fullresolution input image and the color and position models. Here, $P_{\text {position }}$ denotes the up-scaled version of the position model (Fig 4-c), and $P_{\text {colorFinal }}$ is the final color probability, computed by a 3D Gaussian function centered at the spatiallyvarying color given by the up-scaled version of the color model (Fig 4-b).

\section{REsults AND CONCLUSIONS}

We applied the proposed algorithm and the methods from [3] and [4] to a test set of 62 manually annotated images. Fig. 3 compares the ROC curve (true-positive vs. false-positive rates) of the three algorithms. It can be seen that the proposed algorithm yields better results almost along the entire curve. At $10 \%$ false positive rate, the true positive rate of our algorithm yields $91 \%$, vs. $66 \%$ of [3] and $58 \%$ of [4].

Fig. 5-top demonstrates the improved segmentation result by rejecting the trees. This improvement is the result of a more compact representation of the grass color, using PCA analysis. Fig. 5-bottom illustrates the improved segmentation result in sunny and shadow areas.
We conclude that the proposed algorithm outperforms the existing methods in correctly rejecting non-grass, and correctly detecting grass areas under different illumination conditions, due to better color and texture features and the employed modeling. Furthermore, high computational demands have been avoided by performing the modeling in low resolution.

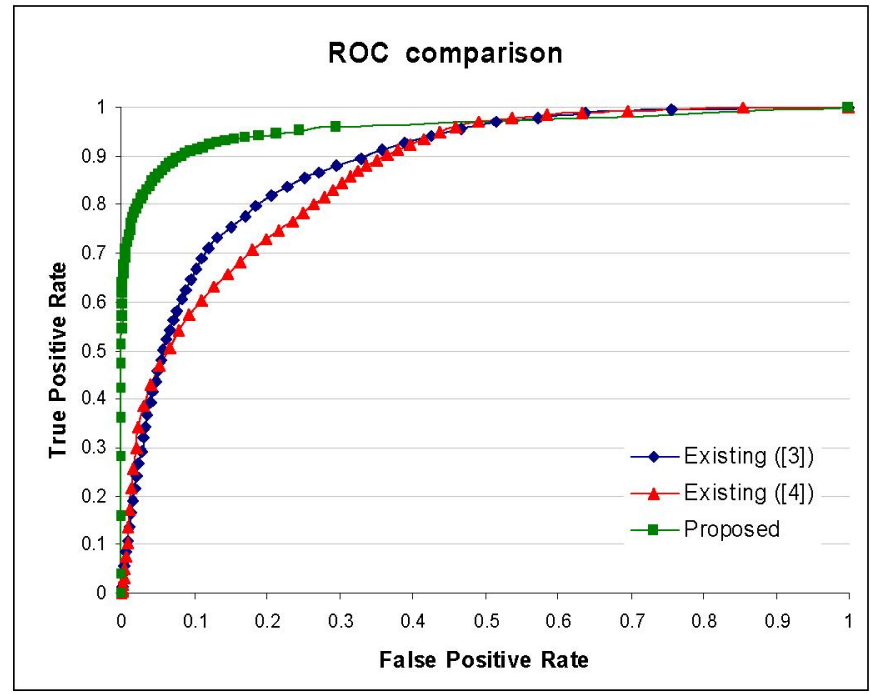

Fig. 3. Performance comparison of the proposed and existing algorithms.

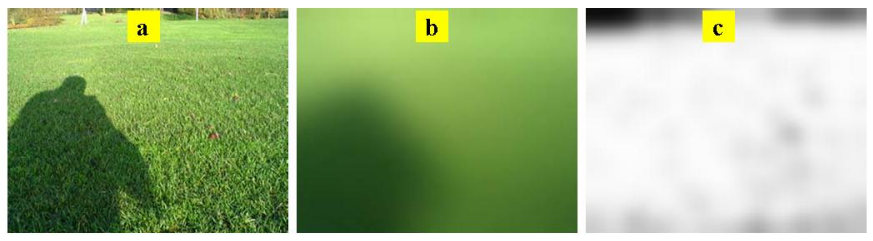

Fig. 4. a: input, b: color model, c: position model.

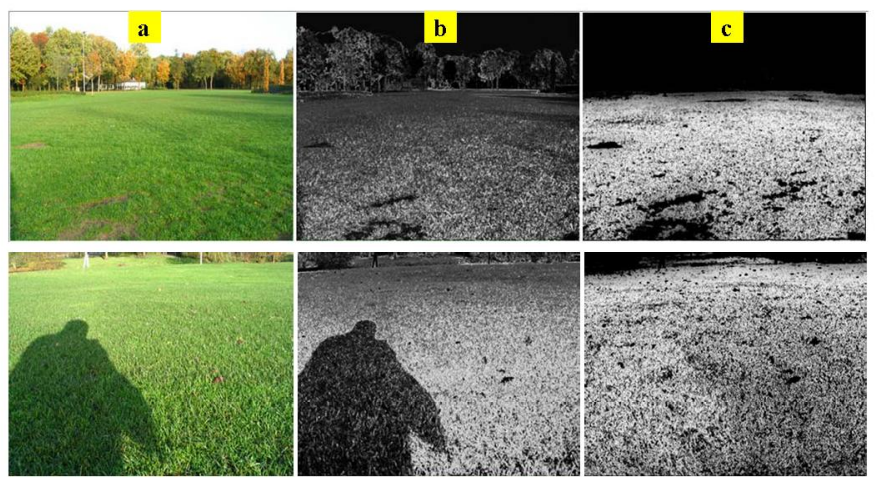

Fig. 5. Sample result: a: input, b: result from [3], c: result proposed algorithm.

\section{REFERENCES}

[1] G. de Haan, "Video Processing for Multimedia Systems", University Press Eindhoven, 2000.

[2] Bahman Zafarifar and Peter H. N. de With, "Blue Sky Detection for Content-based Television Picture Quality Enhancement", IEEE Intern. Conference on Consumer Electronics, January 2007, pp. 1-2.

[3] S. Herman and J. Janssen, "Automatic segmentation-based grass detection for real-time video", European Patent EP 1374 170, date of publication: January 2004.

[4] S. Herman and E. Bellers, "Image segmentation based on block averaging", United States Patent US 2006/0072842 Al, date of publication: April 2006. 